\title{
POZA GIRL POWER: DZIEWCZYŃSKI OPÓR, KONTRPUBLICZNOŚCI I PRAWO DO MIASTA
}

\author{
AGATA LISIAK
}

\begin{abstract}
Abstrakt: Polityczny potencjał siły dziewczyńskości nie tkwi w sile jednostki, ale w dostrzeżeniu wspólności i wielości dziewczyńskich doświadczeń. Odrzucenie postawy heroicznej i wyjście poza indywidualistyczny paradygmat girl power pozwalają na uwidocznienie różnych, nierzadko sprzecznych ze sobą narracji i reprezentacji składających się na współczesne dziewczyństwo, co z kolei pozwala nie tylko na identyfikację kompleksowych mechanizmów wykluczenia, ale też wytworzenie inkluzywnych taktyk i strategii oporu wobec nich. W oparciu o literaturę feministyczną oraz przykłady dziewczyńskiego oporu z kultury popularnej staram się pokazać, w jaki sposób dziewczyny, dokonując interwencji w miejscach zakodowanych jako męskie, łamią kody kulturowe, płciowe, rasowe i klasowe, stawiają opór, przechwytuja narracje o sobie samych i egzekwuja swoje prawo do miasta. Choć niektóre z omawianych przeze mnie gestów, taktyk i strategii mogą się wydawać zbyt łagodne, żeby mieć siłę polityczną, proponuję, że właśnie tym niepozornym formom wyrażania oporu warto się bliżej przyjrzeć, stosując w ich analizie kategorię kontrpubliczności i upłciowionego prawa do miasta.
\end{abstract}

Słowa kluczowe: dziewczyństwo, opór, prawo do miasta, feminizm, kontrpubliczności, heroizm, girl power 


\section{Wprowadzenie}

$\mathrm{Na}$ przestrzeni kilku ostatnich lat pojawiło się sporo nowych książek dla dzieci prezentujących krótkie biografie dziewczyn i kobiet, których życiorysy i dokonania przedstawiane są jako wybitne, oryginalne, inspirujące. W odróżnieniu od zalewających półki księgarni i bibliotek książek o białych księżniczkach, w Tupeciarach Penelope Bagieu (2018) czy Opowieśsiach na dobranoc dla mtodych buntowniczeek Eleny Favilli i Franceski Cavallo (2017) obok księżniczek, królowych i faraonek znajdziemy też dziewczyny niebiałe, dziewczyny z klas ludowych i średnich, dziewczyny z niepełnosprawnościami, dziewczyny z krajów tzw. globalnego południa, dziewczyny trans, dziewczyny queerowe, dziewczyny w hidżabach. Ta otwartość na różne biografie wydaje się być wzbogacająca nie tylko dla dzieci ze zmarginalizowanych grup, którym być może łatwiej jest się odnaleźć w niektórych z tych celebrowanych postaci, niż w kolejnej wersji księżniczki na ziarnku grochu, ale dla wszystkich dzieci oraz osób dorosłych, które im czytaja. Autorki i ilustratorki tych książek przypominaja nam strona po stronie, że nie wszystkie dziewczynki są białe, zamożne, sprawne, mieszkają na zachodzie i marzą o królewiczach. Zastanawiające jest natomiast to, że każda z tych książek skupia się na sile jednostek, na niesamowitości pojedynczych dziewczyn, na ich indywidualnym bohaterstwie, a nie na sile wynikającej z dziewczyńskiej wspólnoty, współpracy czy solidarności.

Jak wskazuje Ewa Majewska w Kontrpublicænośsiach ludowych i feministycznych (2018), historie pojedynczych kobiet zebrane w jednym kontekście moga mieć niesamowita moc polityczną: tak było w przypadku czarno-białych zdjęć selfie wrzucanych przez Polki i ich sprzymierzeńców w kontekście czarnych protestów czy w przypadku biogramów działaczek Solidarności zebranych i wyeksponowanych przez Europejskie Centrum Solidarności i wymienionych performatywnie przez Majewską (2018, 81-83); podobnie jest też w przypadku spopularyzowanych przez hashtag \#metoo wypowiedzi rozmaitych kobiet, które doświadczyły i doświadczają dyskryminacji i przemocy seksualnej. Buntowniczość celebrowana przez wspomniane książki dla dzieci nie powinna być natomiast uznawana za zaletę polityczną samą w sobie, ponieważ książki o „kobietach, które robią to, co chcą”, „dziewczynach, które myślą o wszystkim”, „niedobrych dziewczynkach na przestrzeni wieków” czy „nieustraszonych pionierkach zmieniających świat” (cytaty pochodza z podtytułów omawianych tu publikacji) pośrednio lub bezpośrednio popularyzują postawę girl power w jej skomercjalizowanej, zindywidualizowanej i odpolitycznionej wersji. 
Analizując szereg przykładów dziewczyńskiego oporu występujących w kulturze popularnej, postaram się wskazać, że polityczny potencjał siły dziewczyńskości nie tkwi w sile jednostki, ale w dostrzeżeniu wspólności i wielości dziewczyńskich doświadczeń. Odrzucenie postawy heroicznej i wyjście poza indywidualistyczny paradygmat girl power pozwalaja na uwidocznienie różnych, nierzadko sprzecznych ze sobą narracji i reprezentacji składających się na współczesne dziewczyństwo, co z kolei nie tylko umożliwia identyfikację kompleksowych mechanizmów wykluczenia, ale też wytworzenie solidarnych taktyk i strategii oporu wobec nich. Zaczynając od dyskusji na temat girl power i wskazując na różne ograniczenia tej postawy, ale też możliwości ich przezwyciężenia, przedstawię swoje rozważania na temat dziewczyńskiego oporu dokonywanego w przestrzeni publicznej, szczególnie tej miejskiej. W oparciu o literaturę feministyczną, głównie z zakresu geografii feministycznej, zwracam uwagę na dziewczyńskie formy oporu postulujące prawo do miasta. Przedmiotem mojej analizy nie jest jednak odpłciowione prawo do miasta, o którym pisał Henri Lefebvre (1996), a później David Harvey (2003, 2013) oraz wielu innych teoretyków i teoretyczek miasta (m.in. Marcuse 2009; Mayer 2009; Purcell 2002); chcę raczej wskazać, jak różne formy dziewczyńskiego oporu uwypuklaja płciowe wymiary prawa do miasta (Fenster 2005; Vacchelli i Kofman 2018) i jak domagaja się prawa do miasta na własnych zasadach (Solnit 2016). Kluczowe w dyskusji na temat politycznego potencjału odheroizowanej dziewczyńskości będą też odwoływania do tekstów Ewy Majewskiej na temat feministycznych kontrpubliczności (2018) oraz dziewczyńskich wymiarów prekariatu (2017). Zakończę krótkim nawiązaniem do ruchu \#metoo (Verso Report 2018).

\section{Girl power}

Girl power odwołuje się jednego ze sloganów subkultury riot grrrls, powstałej w Stanach Zjednoczonych we wczesnych latach 90. Do najbardziej znanych przedstawicielek tego ruchu można zaliczyć osoby związane z takimi zespołami, jak Bikini Kill, Huggy Bear, Bratmobile, Heavens to Betsy czy Sleater-Kinney. Prawdopodobnie najbardziej rozpoznawalna postacią z riot grrl jest Kathleen Hanna, współzałożycielka Bikini Kill, później Le Tigre, a obecnie The Julie Ruin. Powstanie i rozwój riot grrrl można odczytywać jako protest przeciw popularnemu wówczas w ich kontekście kulturowym przekonaniu, że feminizm umarł (Marcus 2010). 
Ruch riot grrrl oraz związany z nim kulturowo amerykański feminizm trzeciej fali (jak ochrzciła go Rebecca Walker) dostrzegły moc sprawczą w powszechnie kojarzonej z dziewczyńskością kruchości i podatności na zranienie oraz nadały dziewczyńskości nowe, polityczne znaczenia (Walker 1995; Baumgardner i Richards 2000). Sprzeciwiając się protekcjonalnym użyciom słowa „dziewczyna” i uprzedmiotowiającym reprezentacjom wizualnym młodych kobiet $\mathrm{w}$ heteronormatywnych, patriarchalnych kontekstach oraz wyrażając opór wobec masowego utowarowienia dziewczyńskości w późnym kapitalizmie, riot grrrls domagały się natychmiastowej rewolucji w dziewczyńskim stylu - stylu, które same tworzyły i określały (Marcus 2010). Domagały się dostrzeżenia i docenienia siły w gestach, rzeczach i zachowaniach powszechnie kojarzonych $\mathrm{z}$ dziewczynami oraz nie wahały się podkreślać dziewczyńskiej seksualności na własnych zasadach (Baumgardner i Richards 2000; Hernández i Rehman 2002). Otwarcie i głośno mówiły też o seksizmie, heteropatriarchacie i kulturze gwałtu.

Dziewczyńskość praktykowana przez uczestniczki ruchu riot grrrl opierała się na solidarności, empatii, wspieraniu siebie nawzajem, wspólnym działaniu i tworzeniu tzw. bezpiecznych przestrzeni. Rozwijając strategie wzajemnego wsparcia, riot grrrls odrzucały rywalizacje między dziewczynami. W zinach i ulotkach rozdawanych na koncertach oraz w tekstach swoich piosenek zespoły takie jak Bikini Kill wyjaśniały, czego oczekują od rewolucji w dziewczyńskim stylu i przedstawiały manifesty riot grrrl. Podkreślając, że nie mają wyłączności na to, czym jest promowany przez nie ruch i że riot grrrl nie jest marką, zachęcały inne dziewczyny do pisania własnych manifestów.

Choć to wspólnota, a nie indywidualizm czy heroizm były podstawą działalności riot grrrl, późniejsza - a w zasadzie praktycznie natychmiastowa - popularyzacja girl power opierała się na jej zindywidualizowanej, odpolitycznionej wersji i obejmowała masową produkcje szablonów i metek. Prawdopodobnie najbardziej widoczne było to w estetyce girl bandów z lat 90. zeszłego stulecia, takich jak słynne Spice Girls, w którym każda w pięciu członkiń prezentowała zredukowany do kilku uproszczonych cech typ dziewczyny - typ, który można łatwo konsumować, kupując odpowiednie atrybuty. W odróżnieniu od riot grrrls, które kwestionowały i przełamywały heteronormatywne wzorce kobiecości, dziewczyny ze Spice Girls wydawały się doskonale w nie wpisywać.

Przyczyn masowego odpolitycznienia pojęcia girl power można się dopatrywać w niektórych elementach samego ruchu riot grrrl, który przez nierozpracowane sprzeczności, 
przemilczenia i pominięcia okazał się szczególnie podatny na przechwycenie i utowarowienie. Jednym z takich elementów jest swoisty kult jednostki zawarty w tekstach wielu piosenek riot grrrls (w tym popularnej „Rebel Girl” Bikini Kill, gdzie tytułowa buntowniczka jest bezgranicznie uwielbiana i nazywana królowa), jak i na obrazach powielanych w zinach. Warto też podkreślić, że wbrew deklaracjom o inkluzywności, dostrzeganiu własnej uprzywilejowanej pozycji i otwarciu na nowe członkinie oraz sprzymierzeńców, ruch riot grrrl sprawia wrażenie ruchu białych dziewczyn z przedmieść (Schilt 2003). Można starać się to tłumaczyć specyfiką demograficzną miejsc takich, jak białe miasteczko Olympia w stanie Waszyngton, powszechnie uznawane za kolebkę riot grrrl, czy wszechobecną segregacją rasową w wielu amerykańskich miastach. Można też próbować wyjaśniać białość ruchu riot grrrl iluzją, której mogła ulec biała część pokolenia wychowanego na Ulicy Sezamkowej, talk showach Oprah Winfrey i MTV: przekonaniu, że rasizm skończył się w latach 60.

Choć niektóre z riot grrrls przyznały po latach, że ich ruch rzeczywiście był bardzo biały (Schilt 2003), powielanie takiej opinii jeszcze bardziej marginalizuje doświadczenia i twórczość czarnych dziewczyn, które mimo wszystko brały w nim udział. Jak zauważa Gaby Bess (2015), w słynnym archiwum riot grrrl, zebranym przez Lisę Darms i umieszczonym w New York University jest tylko jeden zin stworzony przez czarną dziewczynę: GUNK. Jego autorka, Ramdasha Bikceem, przeprowadza intersekcjonalną analizę swojej pozycji w riot grrrl - i szerzej w amerykańskim społeczeństwie - oraz zwraca uwagę na różnorodne wykluczenia, których doświadczała. Podobnie, jak Bikceem, muzyczka Tamar-kali Brown wspomina w wywiadzie z Bess (2015), że choć jak najbardziej sympatyzowała z ogólnym przekazem riot grrl, jako czarna dziewczyna nie potrafiła się odnaleźć w ich tekstach, dlatego też współzałożyła Sista Grrrl’s Riot.

Odpolitycznione, wybielone i oderwane od swoich antykonsumpcyjnych, związanych z kulturą DIY początków hasło girl power zostało wchłonięte przez kulturę popularną, od muzyki rozrywkowej przez telewizję, po film i modę (Klein 2000; Gill 2007). Wykreowany w ten sposób model asertywnej, nieustraszonej, dającej sobie ze wszystkim radę, nie potrzebującej niczyjej pomocy, wyzwolonej i szczęśliwej dziewczyny aktywnie przyczynia się produkcji neoliberalnego dziewczyńskiego podmiotu (McRobbie 2015). Jak przekonuje Ewa Majewska w tekście „Prekariat i dziewczyna”, powszechny zachwyt nad dziewczyńską siłą wskazuje zarówno na „uwikłanie współczesnej kultury w konsumpcjonizm, prezentujący się jako (pozorna) emancypacja kobiet” (2017, 154), jak i na „sztywny indywidualizm” (2017, 
185), w którego produkcji współuczestniczy wspominany wcześniej feminizm trzeciej fali. Dyskursy indywidualizujące sukcesy i porażki dziewczyn próbujących sprostać normom odpolitycznionej wersji girl power wpisuja się w neoliberalną logikę, według której to rynek determinuje wszystkie wartości, również te społeczne (Gonick 2006).

\section{Dziewczyny a prawo do miasta}

W swojej książce Space, Place and Gender (1994) marksistowska geografka feministyczna Doreen Massey wspomina, jak w wieku dziewięciu lat zrozumiała, co to znaczy być dziewczyną w mieście. Massey dorastała na przedmieściach Manchesteru, każda wyprawa do miasta była dla niej sporym wydarzeniem i wydawała się trwać długo, bo aż całe pół godziny. Podczas tych rodzinnych wyjazdów do miasta mała Massey siadała na górnym piętrze autobusu i z tej wysokości obserwowała okolicę, spoglądając na mijane po drodze boiska do piłki nożnej i rugby, które ciagnęły się aż po horyzont. Massey wspomina, że podczas jednej z takich wypraw dotarło do niej, że ta olbrzymia przestrzeń pomiędzy przedmieściami a miastem została w całości oddana we władanie chłopcom, a dla niej wydawała się niedostępna. Massey przyznaje, że jako dorosła kobieta nie miała już problemu z dokonywaniem inwazji miejsc zakodowanych kulturowo jako męskie, takich jak na przykład stadiony piłki nożnej; jako dziewczynka nie odważała się jednak na takie gesty.

Massey podkreśla, że zarówno przestrzeń, jak i konkretne miejsca oraz nasze poczucie miejsca (sense of place) są na wskroś upłciowione, przy czym „upłciowienie przestrzeni i miejsca nie tylko odzwierciedla, ale też wpływa na to, w jaki sposób płeć jest konstruowana i rozumiana" $(1994,186)$. Miejskie miejsca nie są zbiornikami, w których rzeczy po prostu się dzieją. Miejska codzienność, zarówno ta przeżywana w przestrzeni publicznej, jak i prywatnej, jest upłciowiana przez nasze praktyki i doświadczenia. Inna geografka feministyczna, Tovi Fenster, dokonuje rewizji klasycznego, lefebvriańskiego znaczenia pojęcia „prawo do miasta”, zwracając uwagę na to, w jak ogromnym stopniu jest ono ukształtowane przez nacechowane etnicznie, narodowo i płciowo patriarchalne relacje władzy. Pisząc o „prawie do upłciowionego miasta" (right to the gendered city) Fenster (2004) podkreśla, że prawo do przestrzeni publicznej jest blisko powiązane z prawem do przestrzeni prywatnej i nie powinno się ich analizować oddzielnie. Jak przekonuje Fenster, patriarchalne relacje władzy 
wyznaczaja „granice przynależności” $(2004,229)$ dla kobiet i innych osób marginalizowanych, tym samym ograniczając ich prawo do miasta.

W przytaczanych poniżej przykładach staram się pokazać, w jaki sposób, dokonując inwazji miejsc zakodowanych jako męskie, łamiąc kody kulturowe, płciowe, rasowe i klasowe, stawiając opór, dziewczyny przechwytują narracje o sobie samych i egzekwują swoje prawo do miasta. Przyglądając się gestom i taktykom wykształconym przez dziewczyny w różnych kontekstach historycznych i kulturowych, zwracam uwage na wspólność i wielość form dziewczyńskiego oporu. To właśnie konkretne gesty i taktyki, a nie porządek chronologiczny czy geograficzny ich występowania są spoiwem łączącym omawiane przeze mnie przykłady.

\section{Dziewczyny wychodzą ze swoich pokojów}

W analizie brytyjskich subkultur dziewczyńskich lat 70. zeszłego stulecia, Angela McRobbie i Jenny Garber (1991) wielokrotnie podkreślały, że znaczenie dla ich rozwoju miało nie tylko to, co się działo na ulicy, ale też to, co się działo w pokojach tych dziewczyn. Opowiadając o swojej solowej płycie The Julie Ruin, Kathleen Hanna wspomina, że chciała, żeby jej album brzmiał tak, jakby mogła go stworzyć jakakolwiek dziewczyna mająca potrzebę szczerego wypowiedzenia swoich myśli i uczuć (Anderson 2013). Hanna rzeczywiście nagrała cały album w swoim pokoju, sugerując i wyrażając nadzieję, że wiele innych dziewczyn zrobi to samo: „pokoje dziewczyn są przestrzeniami kreatywności. Problem polega na tym, że te pokoje są od siebie odcięte"1 (Hanna w Anderson 2013). Hanna wydaje się wskazywać tutaj na polityczny sens girl power: generowanie politycznej siły poprzez dostrzeganie wspólnych doświadczeń i zrozumienie, że problemy, które mogą nam się wydawać bardzo osobiste, mają konkretne, strukturalne uwarunkowania i że nie tylko można, ale też trzeba o tym głośno mówić, krzyczeć, stawiać opór i zmieniać zasady gry. Niektóre formy dziewczyńskiego oporu mogą się wydawać zbyt zwyczajne czy łagodne, żeby mieć siłę polityczną - i właśnie tym niepozornym formom oporu chciałabym się teraz przyjrzeć.

W jednym z centralnych punktów Biszkeku znajdziemy górującą nad okolicą alegorię rewolucji oraz dwie umieszczone na granitowych cokołach grupy rzeźb przedstawiające

1 Wszystkie tłumaczenia $z$ angielskiego pochodzą od autorki. 
męczenników rewolucji, na których cześć został nazwany cały plac. W zeszłym roku, podczas wizyty w kirgiskiej stolicy, miałam okazję przyjrzeć się poszczególnym elementom tego placu. Moja uwage przykuły wykonane permanentnymi mazakami napisy na granitowych cokołach: większość z nich stanowiły deklaracje heteroseksualnej miłości, z imionami zakochanych oprawionymi w serca. Wśród tych serc było jedno szczególne, zawierające cztery żeńskie imiona: Janka, Alya, Salya, and Firu oraz napisane po angielsku zdanie „love is my friend”. To niewielkie graffiti było nie tylko celebracją dziewczyńskiej przyjaźni, ale też formą oporu, zarówno wobec normy, jaką jest heteroseksualna miłość, jak i wobec zawładnięcia przestrzeni miejskiej przez państwowe narracje. Tym drobnym gestem dziewczyny zaznaczyły swoja obecność w centralnym punkcie Biszkeku i zrobiły to na swoich zasadach.

Proponuję myśleć o tym niepozornym graffiti nie tylko jako przypomnieniu o obecności dziewczyn i dziewczyńskości w mieście zaplanowanym i rządzonym przez heteropatriarchat, ale też wyrazie dziewczyńskiego oporu wobec symbolicznych wykluczeń, których co dzień doświadczają. Jak zauważa Rebecca Solnit w eseju „Miasto kobiet”, przestrzeń miejska jest upłciowiana nie tylko przez codzienne praktyki, a też przez nazwy ulic, skwerów czy budynków: nasze miasta są pełne męskich imion i nazwisk, na każdym kroku przypominających o tych, którzy sprawowali władzę, tworzyli historię czy zdobywali fortuny. Przemieszczając się po mieście, chodzimy ulicami nazwanymi na cześć generałów, papieży, ministrów, prezydentów, królów i pisarzy. Solnit zachęca nas do wyobrażenia sobie, jak by się żyło w mieście dziewczynom, gdyby mijane i zamieszkiwane przez nich miejsca nosiły żeńskie imiona. $\mathrm{Na}$ alternatywnej mapie nowojorskiego metra towarzyszącej esejowi Solnit nadaje wszystkim stacjom imiona i nazwiska kobiet. Wyobraźmy sobie przejazd metrem ze stacji Assata Shakur na Harlemie do stacji Serena Williams w Queens, albo w Warszawie ze stacji Róża Luksemburg do stacji Anna Jantar.

Może się wydawać, że takie ćwiczenia wyobraźni odwracają uwagę od „naprawdę ważnych spraw", moim zdaniem są jednak potrzebne, by dostrzec skalę systematycznego wyłączania dziewczyn i kobiet z przestrzeni publicznej. Te cztery dziewczyny w Biszkeku, które wypisały swoje imiona na cokole posagu bohaterskich męczenników, egzekwują swoje prawo do miasta: prawo do pełnego korzystania $z$ przestrzeni miejskiej i prawo do decydowania jak ta przestrzeń ma wyglądać i funkcjonować.

We francuskim filmie Bande de filles (reż. Celine Sciamma, 2014), cztery czarne dziewczyny z migranckich przedmieść Paryża (banlieues) negocjuja miejską przestrzeń, 
stawiając opór symbolicznym i fizycznym wykluczeniom ich ciał z miejsc zakodowanych jako męskie, białe czy należące do klasy średniej. W jednej ze scen celebrujących kolektywne doświadczenia zmarginalizowanej dziewczyńskości widzimy liczną grupę głównie czarnoskórych dziewczyn w biznesowej dzielnicy Paryża, La Défense. Zaczynając od zbliżenia twarzy głównej postaci, Marième, kamera prześlizguje się powoli po twarzach jej koleżanek i innych dziewczyn, które wydają się wręcz promieniować radością i siłą wynikająca z bycia razem. W tej otwartej przestrzeni między biurowcami (wiemy, że w jednym z tych biurowców sprząta na nocnej zmianie matka Marième - i być może też matki innych dziewczyn takich jak ona) dziewczyny urządzają dance off - konkurs tańca, w którym prezentują ćwiczone wcześniej godzinami choreografie, chwaląc się przed koleżankami nowymi ruchami, celebrując swoją kreatywność, inspirując się nawzajem. Robią to, o czym pisał Lefebvre: „zamiast tkwić w gettach dla robotników, imigrantów, osób zmarginalizowanych, a nawet osób uprzywilejowanych, egzekwuja swoje prawo do korzystania z uprzywilejowanego miejsca, jakim jest centrum miasta" (1996, 34). Istotne jest jednak przy tym nie tylko to, że w ogóle korzystaja z centrum, ale też sposób, w jaki to robia.

Jak w innych scenach z filmu Sciammy, tak i tutaj dziewczyny egzekwuja swoje prawo do bycia widzianymi i słyszanymi: w drodze do La Défense wypełniają swoimi ciałami całą długość schodów ruchomych i całą szerokość korytarza w centrum handlowym, a będąc już na placu, radośnie tańczą do głośnej muzyki. Nie sposób ich nie zauważyć, nie sposób ich nie usłyszeć, nie sposób przejść obok o nich obojętnie. Taniec nastolatek z biednych paryskich przedmieść w centrum biznesowym miasta można odczytać jako formę dziewczyńskiego oporu przeciw ekonomicznej, kulturowej i płciowej marginalizacji czarnych, migranckich, robotniczych ciał. Jest to opór zarówno wobec marginalizujących je instytucji (państwa, szkoły), jak i marginalizującej je kultury (białej, heteropatriarchalnej i zdominowanej przez klasy średnie). Stosując w analizie tej sceny - jak i wielu innych fragmentów filmu Sciammy kategorię kontrpubliczności zaproponowaną przez Majewska, odczytamy ten „podwójny opór” jako „formę politycznej sprawczości, która zwraca się przeciw istniejącej władzy, zwłaszcza tej instytucjonalnej, choć czasem również przeciw najogólniejszym regułom danej kultury, jak też przeciw liberalnym, jak byśmy dziś powiedzieli, elitom, tworzącym sferę publiczną" $(2018,25)$. 
Mówiąc o tańcu jako formie oporu, warto wspomnieć o działalności szwedzkiego kolektywu performerskiego Juck (ich nazwę, tłumaczoną na angielski jako „thrust”, można próbować przetłumaczyć na polski jako „popychać” lub „pchnięcie”). Założony w 2011 roku i zróżnicowany pod względem etniczności i orientacji seksualnej kolektyw regularnie dokonuje interwencji w przestrzeni publicznej: na festiwalach muzycznych i artystycznych, na dworcach i centralnych placach miast, a nawet wewnątrz siedziby szwedzkiego rządu. Nakręcony przez Juck w 2013 roku krótki film cieszy się sporą popularnością na YouTubie, a w zeszłym powstał o nich krótki film dokumentalny, który obecnie jest pokazywany na międzynarodowych festiwalach filmowych. Performensy Juck opierają się na kilku prostych powtarzających się elementach: członkinie kolektywu są ubrane w szkolne, „dziewczęce” mundurki; ich choreografia opiera się głównie na rytmicznym ruchu miednicą do przodu i do tyłu oraz krzyżowaniu przy tym „po męsku” dłoni na karku; patrzą wprost w oczy publiczności lub do kamery; jeśli się uśmiechaja, to tylko do siebie nawzajem. Juck mieszaja elementy zakodowane jako heteronormatywnie dziewczęce $\mathrm{z}$ elementami zakodowanymi jako heteronormatywnie męskie; wychodząc poza binarne podziały płciowe, queerują zarówno swoje ruchy, jak i przestrzeń, w której je wykonuja. Jak same o sobie piszą, „w Juck chodzi o swobodę ekspresji, seksualność, zabawę i rozszerzanie perspektyw na temat kobiecości i płci” (Juck 2013) Swoim tańcem Juck nie tylko stawiają opór wobec norm społecznych dosłownie krępującym ruchy dziewczyn, ale też dekodują upłciowienie miejskich przestrzeni.

Rozważania na temat reprezentacji niepozornych form dziewczyńskiego oporu w miejskiej przestrzeni publicznej proponuję zakończyć dyskusją na temat teledysku towarzyszącego popularnej piosence Cyndi Lauper „Girls Just Want to Have Fun”, który poprzedza wymienione powyżej przykłady. Utwór pochodzi z wydanej w 1983 roku debiutanckiej płyty Lauper, której wydawca nie zgodził się na to, żeby wokalistka śpiewała na niej swoje własne piosenki. Choć została zmuszona do nagrania wyłącznie utworów napisanych przez mężczyzn, Lauper udało się wynegocjować zmianę tekstu piosenki, która wkrótce miała okazać się hitem. Z mizoginicznego tekstu o „łatwych dziewczynach”, które marzą o zaspokajaniu potrzeb seksualnych męskiego wykonawcy piosenki, stworzyła utwór o tym, że po długim dniu w pracy dziewczyny chcą zabawy na własnych zasadach.

W przerysowanym, przypominającym amerykański sitcom teledysku główna postać grana przez Lauper nie może znaleźć dla siebie miejsca w pełnym moralnych zakazów 
i nakazów domu rodziców i - wbrew ich przestrogom i groźbom - wybiega na nowojorską ulicę, gdzie dołączają do niej koleżanki. Postać grana przez Lauper jest białą dziewczyna z klasy robotniczej; jej koleżanki to dziewczyny różnego pochodzenia etnicznego i klasowego. Będąc z nimi, Lauper niczym specjalnym się nie wyróżnia; razem wydają się kolorowe, mogłyby wręcz pozować do jednej z reklam United Colors of Bennetton. Ich radosny pochód przez miasto ma w sobie coś z karnawału, a jego wyjątkowy nastrój udziela się wielu napotkanym po drodze osobom. Dziewczyny stawiaja „,podwójny opór” (Majewska 2018) nie tylko wobec instytucji rodziny, ale też wobec kulturowym, klasowym i płciowym normom obowiązującym w przestrzeni publicznej.

Jak zauważa Marshall Berman w tekście „Take It to the Streets: Conflict and Community in Public Space”, dziewczyny w teledysku Lauper „nie tylko odmieniają swoje własne życia, ale dokonują też transformacji samej ulicy; wykorzystując strukturalną otwartość miejskiej ulicy umożliwiająca przełamanie barier rasowych, klasowych, wiekowych i seksualnych, dziewczyny i gromadzą radykalnie różnych od siebie ludzi” (2017, 78). W oczach Bermana teledysk Lauper jest realizacja ,kolektywnego marzenia o tym, jak powinna wyglądać przestrzeń publiczna" (2017, 77). Dziewczyny nie tylko odmieniają ulicę, ale też przynosza ja - w tej egalitarnej, inkluzywnej wersji - do domu rodziców Lauper, przezwyciężając w ten sposób, jak twierdzi Berman, dychotomię prywatnego i publicznego.

Berman nie kryje zachwytu nad tą teledyskowa celebracją ulicy jako miejsca różnorodnego i otwartego; podkreśla też, że mijani przez dziewczyny robotnicy budowlani wcale ich nie zaczepiaja: „ku naszemu zdziwieniu i radości, robotnicy jedynie przyjaźnie się uśmiechaja, a niektórzy z nich - co zdumiewa jeszcze bardziej - nawet odrzucaja narzędzia i dołączają do tańczącego pochodu” $(2017,78)$. Nasuwa się tutaj pytanie, którego Berman w tym całym zachwycie i zdziwieniu jakoś sobie nie stawia: czy postać grana przez Lauper mogłaby dokonać transformacji (zarówno siebie, jak i ulicy) bez pozostałych dziewczyn? Ich przyjaźn jest nie tylko narzędziem pomagającym przełamać i skomplikować dychotomię prywatnego i publicznego, o czym pisze Berman, ale też zwyczajnie strategia przetrwania w mieście. 


\section{Dziewczyński opór a opór podporządkowanych innych}

Nie jest chyba tajemnica, że przemieszczanie się po mieście jest dla dziewczyn bezpieczniejsze w grupie niż w pojedynkę. Wszystkie znane mi kobiety i dziewczyny - moje przyjaciółki, ciotki, studentki, sąsiadki - jak i ja sama mamy bez liku historii o nieproszonych męskich interwencjach w naszą przestrzeń, w nasz czas, w nasze ciała, których doświadczamy idąc ulica, mostem, przejściem podziemnym; siedząc na ławce w parku i na przystanku, w metrze i w autobusie; czytając książkę w tramwaju; uprawiając jogging w parku; jadąc rowerem do pracy i na działkę; pchając przed sobą wózek z dzieckiem i ciągnąc za sobą walizkę na kółkach; nic nie robiąc, po prostu będąc. Jak pisze przywoływana wcześniej Rebecca Solnit, przez powszechnie doświadczane zaczepki i molestowanie, dziewczynom przypomina się na każdym kroku, że „to nie jest ich świat, to nie jest ich miasto, to nie jest ich ulica; że ich swoboda ruchu może być w każdej chwili zakwestionowana i że wielu nieznajomych wymaga od nich posłuszeństwa i uwagi” $(2016,85)$.

Ruch \#metoo, zainicjowany w 2006 roku w Stanach Zjednoczonych przez afroamerykańską aktywistkę Taranę Burke i spopularyzowany przez białe hollywoodzkie aktorki w 2017 roku na fali oskarżeń o molestowanie seksualne i gwałt skierowanych masowo przeciw producentowi filmowemu Harveyowi Weinsteinowi (a później także innym mężczyznom), jest jedną $z$ wielu akcji zwracających uwagę na skalę i rozmaite formy przemocy seksualnej wobec kobiet i innych marginalizowanych osób (Adetiba i Burke 2017; Verso Report 2018). Znane szerokiej, globalnej publiczności twarze zamożnych, białych, zachodnich aktorek, mówiące ,ja też” bezsprzecznie pomogły nagłośnić powszechność problemu dyskryminacji seksualnej kobiet. Lokalne wersje hashtagu \#metoo - \#JaTeż w Polsce, \#Balance'TonPorc we Francji czy \#QuellaVoltaChe we Włoszech - pomagaja przeprowadzić ważne interwencje i debaty publiczne na temat kultury gwałtu, molestowania seksualnego i kwestii zgody na seks.

Nie dyskredytując indywidualnych cierpień osób, które podzieliły się swoimi doświadczeniami przemocy na fali \#metoo, warto podkreślić, że kobiety od wieków mówią, pisza, śpiewają i krzyczą o przemocy seksualnej. Szczególnie narażone na przemoc seksualną były i nadal są dziewczyny i kobiety zmarginalizowane pod względem rasowym, ekonomicznym, edukacyjnym, geograficznym, seksualnym i sprawnościowym. Jedną z bohaterek wspomnianych przeze mnie na wstępie książek dla dzieci jest Rosa Parks, 
znana głównie z tego, że w 1955 roku, w okresie usankcjonowanej prawnie segregacji rasowej na południu Stanów Zjednoczonych, odmówiła ustappienia miejsca w autobusie białej osobie. Mniej znany jest natomiast fakt, że na długo zanim stała się ikoną ruchu praw obywatelskich, Parks była działaczką dokumentująca przemoc seksualną wobec czarnych kobiet i że sama jako młoda osoba doświadczyła takiej przemocy ze strony białego pracodawcy (McGuire 2018). Wieloletnie zaangażowanie Rosy Parks w działalność antyrasistowską i feministyczną oraz jej osobiste doświadczenia dyskryminacji zostały w wyobraźni popularnej spłycone do jednego gestu odczytywanego jako heroiczny i buntowniczy.

Jako że popularność ruchu \#metoo wydaje się obecnie opierać na zwierzeniach głównie białych kobiet z klas średnich i wyższych, dostrzegam potrzebę przełamania tej dyskursywnej dominacji i zwrócenia uwagi na sprawczość polityczną osób zmarginalizowanych, które doświadczają przemocy seksualnej. Jak zwracają uwage poetka Tishani Doshi (2018) i pisarka Arundhati Roy (2012), mierzące się w swoich tekstach z kulturą gwałtu w Indiach, do międzynarodowego mainstreamu rzadko docieraja głosy podporządkowanych innych, które najdotkliwiej doświadczają przemocy. W wierszu „Dziewczyny wychodza z lasów” (Girls are coming out of the woods) Doshi upamiętnia nie tylko nagłośniony przez globalne media zbiorowy, morderczy gwałt na Jyoti Singh Pandey w Delhi w grudniu 2012 roku, ale też wiele innych nazwanych i nienazwanych aktów przemocy wobec dziewczyn i kobiet, szczególnie tych ze zmarginalizowanych grup (Roy 2012).

Dziewczyny wychodzą z lasów,

owite w peleryny i kaptury,

niosą żelazne pręty i świece

i bezmiar blizn zebranych

na hektarach przedwczesnej trawy i w miejskich

autobusach, w świątyniach i barach. (...) (Doshi 2018) 
Odnosząc się w poetycki, mitologizujący sposób do pojedynczych gestów oporu i protestu, Doshi zwraca uwagę nie tylko na powszechność przemocy doświadczanej przez dziewczyny i kobiety, ale też na potencjał wyobraźni politycznej tkwiącej $\mathrm{w}$ tych gestach i na sile wynikającej z dostrzeżenia wspólności doświadczeń. Warto tutaj wrócić do wspomnianej wcześniej kategorii kontrpubliczności, która, jak przekonuje Majewska, „pozwala nie tylko wskazać grupy [podporządkowanych innych], ale też omówić ich działanie" (2018, 72). Podkreślając znaczenie niehegemonicznych strategii i form wyrażania oporu, kategoria kontrpubliczności umożliwia analizę sprawczości politycznej podporządkowanych innych.

\section{Zakończenie: odheroizowana siła dziewczyn}

Wzorce dziewczyńskości wykreowane przez girl power okazują się niewystarczające do utworzenia nowej wyobraźni politycznej, ponieważ zbyt mocno opierają się na rzekomej wyjątkowości doświadczeń pojedynczych dziewczyn zamiast na tym, co je łączy. Bohaterki są nam równie mało potrzebne, jak bohaterowie.

Odrzucając zarówno heroizm, jak i postawę ofiary, omówione przeze mnie formy dziewczyńskiego oporu podkreślają wspólność i wielość doświadczeń opresji, dyskryminacji i przemocy. Dostrzegając i upolityczniając tę wspólność i wielość doświadczeń, dziewczyński opór nie tylko uwidocznia, ale też przekracza strukturalne, wpisane w miejską przestrzeń publiczną ograniczenia wynikające z nierówności na tle płciowym, rasowym, klasowym czy seksualnym.

Zastanawiając się nad tym, jak dziewczyńskie formy oporu pomagają wykształcić nową wyobraźnię polityczną, warto rozważyć, jakie kryteria stosujemy w ocenie ich sprawczości. Jeśli miarą sukcesu ma być natychmiastowa, radykalna zmiana, przytoczone przeze mnie przykłady należałoby uznać za totalne porażki. Jeśli jednak, jak proponuje Majewska, zmienimy kryteria oceny tych zmian i, wychodząc poza dychotomię reformy i rewolucji, skupimy się ich mniej oczywistych elementach, które starałam się tutaj przybliżyć, dostrzeżemy „rozmiary i wieloaspektowość przekształcania tego, co politycznie nośne” (2018, 304). 


\section{Wykaz literatury}

Adetiba, Elizabeth i Tarana Burke. 2017. „Tarana Burke Says \#MeToo Should Center Marginalized Communities": https://www.thenation.com/article/tarana-burke-saysmetoo-isnt-just-for-white-people/

Anderson, Sini (reż). 2013. The Punk Singer.

Bagieu, Pénélope. 2018. Tupeciary: O kobietach, które robiq to, co chca, tłum. Agnieszka PączkaTorelli i Anna Pączka. Warszawa: bęc zmiana.

Baumgardner, Jennifer, i Amy Richards. 2000. Manifesta: Young Women, Feminism, and the Future. Nowy Jork: Farrar, Straus and Giroux.

Berman, Marshall. 2017. „Take it to the Streets: Conflict and Community in Public Space.” W Modernism in the Streets: A Life and Times in Essays, red. Marcus, David, i Shellie Sclan. Londyn: Verso.

Bess, Gabby. 2015. „Alternatives to Alternatives: the Black Grrrls Riot Ignored.” https://broadly.vice.com/en_us/article/9k99a7/alternatives-to-alternatives-the-blackgrrrls-riot-ignored

Doshi, Tishani. 2018. Girls Are Coming Out of the Woods. Hexham: Bloodaxe Books.

Favilli, Elena, i Francesca Cavallo. 2017. Opowieści na dobranoc dla mtodych buntowniczek, thum. Ewa Borówka. Katowice: Debit.

Fenster, Tovi. 2005. „The Right to the Gendered City: Different Formations of Belonging in Everyday Life." Journal of Gender Studies 14(3): 217-31.

Gill, Rosalind. 2007. „Postfeminist Media Culture: Elements of a Sensibility” European Journal of Cultural Studies 10. 2: 147-166.

Gonick, Marnina. 2006. „Between Girl Power and Reviving Ophelia: Constituting the Neoliberal Girl Subject." NWS A Journal 18.2: 1-23.

Harvey, David. 2003. „The Right to the City.” International Journal of Urban and Regional Research 27.4: 939-941.

Harvey, David. 2013. Rebel Cities: From the Right to the City to the Urban Revolution. Londyn: Verso.

Hernández, Daisy. i Bushra Rehman. 2002. Colonize This!: Young Women of Color on Today's Feminism. New York: Seal Press.

Juck. 2013-. https://www.juck.org

Klein, Naomi. 2000. No Logo: Taking Aim at the Brand Bullies. Toronto: Vintage Canada.

Lefebvre, Henri. 1996. Writings on Cities, tłum. i red. Kofman, Eleonore i Elizabeth Lebas. Londyn: Blackwell.

Majewska, Ewa. 2018. Kontrpubliczności ludowe i feministyczne: Wczesna „Solidarnośc”” i Czarne Protesty. Warszawa: Instytut Wydawniczy Książka i Prasa.

Majewska, Ewa. 2017. „Prekariat i dziewczyna: Fetyszyzm towarowy i emancypacja dziś.” W Tramwaj zwany uznaniem: Feminizm $i$ solidarnośćpo neoliberalizmie. Warszawa: Instytut Wydawniczy Książka i Prasa.

Marcus, Sara. 2010. Girls to the Front: The True Story of the Riot Grrrl Revolution. Nowy Jork: Harper Collins.

Marcuse, Peter. 2009. „From critical urban theory to the right to the city.” City 13.2-3: 185197. DOI: $10.1080 / 13604810902982177$

Massey, Doreen. 1994. Space, Place and Gender. Cambridge: Polity Press.

Mayer, Margit. 2009. ,'The 'Right to the City' in the context of shifting mottos of urban social movements." City 13.2-3: 362-374. DOI: 10.1080/13604810902982755 
McGuire, Danielle L. 2018. „The Maid and Mr. Charlie: Rosa Parks and the Struggle for Black Women's Bodily Integrity." W Verso Report, Where Freedom Starts: Sex, Power, Violence, \#MeToo. London: Verso.

McRobbie, A. (2015) Be Creative: Making a Living in the New Culture Industries. London: Wiley.

McRobbie, Angela i Jenny Garber. 1991. „Girls and Subcultures.” W McRobbie, Angela, Feminism and Youth Culture: From Jackie' to 'Just Seventeen'. Basingstoke: Macmillan. 1-15.

Purcell, Mark. 2002. „Excavating Lefebvre: the right to the city and its urban politics of the inhabitant." Geojournal 58: 99-108.

Roy, Arundhati. 2012. „Arundhati Roy speaks out against Indian rape culture,” https://www.channel4.com/news/arundhati-roy-speaks-out-against-indian-rapeculture

Schilt, Kristen. 2003. „'A Little Too Ironic': The Appropriation and Packaging of Riot Grrrl Politics by Mainstream Female Musicians." Popular Music and Society 26.1: 5-16

Sciamma, Celine (reż.). 2014. Bande de filles Bande de filles.

Solnit, Rebecca. 2016. „City of Women: The Power of Names.” W Solnit, Rebecca, i Joshua Jelly-Schapiro, Nonstop Metropolis: A New York City Atlas. Oakland: University of California Press. 85-90.

Vacchelli, Elena i Kofman, Eleonore. 2018. „Towards an Inclusive and Gendered Right to the City." Journal of Gender Studies 17: 1-3.

Verso Report. 2018. Where Freedom Starts: Sex, Power, Violence, \#MeToo. London: Verso.

Walker, Rebecca. 1995. To Be Real: Telling the Truth and Changing the Face of Feminism. New York: Anchor. 
Agata Lisiak - profesorka w Bard College Berlin, gdzie prowadzi zajęcia z zakresu studiów migracyjnych, socjologii miejskiej, kultury wizualnej, gender studies i socjologii pracy. Była badaczką w Instytucie Nauk Społecznych na Uniwersytecie Humboldtów, stypendystką Marie Curie Actions w wiedeńskim Instytucie Nauk o Człowieku oraz kuratorką w berlińskim Haus der Kulturen der Welt. Jej teksty ukazały się m.in. w Feminist Review; City; Gender, Place and Culture i Widoku. Lisiak jest współzałożycielką migART.

\section{DANE ADRESOWE:}

Migration Studies

Bard College Berlin

Platanenstraße 24

13156 Berlin

EMAIL: a.lisiak@berlin.bard.edu

CytowaniE: Lisiak, Agata. 2019. „Tytuł” Praktyka Teoretycz̨na 2(32): 47-63

DOI: $10.14746 /$ prt.2019.2.3

\section{AUTHOR: Agata Lisiak}

TITLE: Beyond girl power: girl resistance, counterpublics, and the right to the city.

ABSTRACT: Girlhood's political potential does not lie in the power of individual girls, however magnificent, but in acknowledging the commonalities and multiplicities of all girls' experiences. Rejecting the individualistic "girl power" paradigm opens up new, sometimes contradictory narrations and representations of contemporary girlhood. This non-heroic approach to girlhood reveals not only the intricate workings of exclusion mechanisms, but also the various inclusive tactics and resistance strategies at work. Engaging with the concepts of counterpublics, the gendered right to the city, and feminist theory more broadly, I look closely at selected examples of girl resistance from popular culture to demonstrate how girls' interventions in urban places usually coded as masculine can subvert cultural, gender, racial, and class codes, reappropriate narrations about themselves, and execute their right to the city. Even if some of the gestures and tactics I discuss in the paper may seem too mild to have any political power, I propose that it is exactly such unassuming forms of resistance that promise real change and deserve our urgent attention.

KEYWORDS: girlhood, resistance, right to the city, feminism, counterpublics, heroism, girl power 